IJ§ER

ISSN: 2149-5939
International Journal of Social Sciences and Education Research

Online, https://dergipark.org.tr/tr/pub/ijsser

Volume: 7(2), 2021

\title{
The other face of the iceberg: The immigrant students in English courses and their teachers
}

\author{
Oya Tunaboylu ${ }^{\mathrm{a}}$, Merve Vezir ${ }^{\mathrm{b} *}$ and Ayşenur Uluyol ${ }^{\mathrm{c}}$ \\ *Corresponding author \\ ${ }^{a}$ Assoc. Prof., Department of English Language Teaching, Süleyman Demirel University, Isparta, Turkey ORCID: https://orcid.org/0000-0002- \\ 9926-7973, oyatunaboylu@sdu.edu.tr \\ ${ }^{b}$ Department of English Language Teaching, Süleyman Demirel University, Isparta, Turkey, ORCID: https://orcid.org/0000-0002-7037-5778, \\ vezirmerve@icloud.com \\ ${ }^{b}$ Department of English Language Teaching, Süleyman Demirel University, Isparta, Turkey, ORCID: https://orcid.org/0000-0002-4358-6836, \\ aysenuruluyol3@gmail.com
}

\begin{tabular}{|c|c|}
\hline Article Info & Abstract \\
\hline Research Article & $\begin{array}{l}\text { The present qualitative study aimed to provide some insights from common difficulties Eng- } \\
\text { lish language teachers face while working with immigrant children. The research adopted a }\end{array}$ \\
\hline $\begin{array}{l}\text { Received: } 27 \text { November } 2020 \\
\text { Revised: } 7 \text { January } 2021 \\
\text { Accepted: } 17 \text { March } 2021\end{array}$ & $\begin{array}{l}\text { Grounded Theory design. The data were collected from } 6 \text { female English language teachers } \\
\text { working at different types of state schools by using semi-structured in-depth interviews. In- } \\
\text { terviews were first transcribed and emerging categories were analyzed. The findings } \\
\text { showed that difficulties experienced at each school type were different. Teachers developed }\end{array}$ \\
\hline $\begin{array}{l}\text { Keywords: } \\
\text { Immigrant students, } \\
\text { English language course, } \\
\text { Turkish schools, } \\
\text { Teaching immigrants, }\end{array}$ & $\begin{array}{l}\text { various strategies to be able to cope with these difficulties. Based on the data and the find- } \\
\text { ings of the study, a number of recommendations were provided by the researchers and the } \\
\text { participating teachers. It is assumed that the participating teachers' experiences explored } \\
\text { and discussed in this paper will provide baseline information for those teachers who have } \\
\text { newly encountered the phenomenon in their teaching contexts. }\end{array}$ \\
\hline
\end{tabular}
$I C C$

\section{Introduction}

The number of migrants and refugees living in Turkey now stands at 4 million, more than $90 \%$ of whom are Syrian and have come to Turkey as a result of the continuing war in Syria. 3.6 million Syrians, along with other migrants of various nationalities seeking asylum, humanitarian protection or refugee status, have registered for temporary protection in Turkey ("UNHCR Türkiye İstatistikleri - UNHCR Country," n.d.). Children and adolescents living in war zones are often portrayed as a lost, violent and vindictive generation (Qouta et al., 2008). Staying in such a situation naturally affects people of all age groups, but children are more sensitive than adults in terms of making sense of this situation as is well depicted in the following quotation;

In the past, wars were fought between soldiers on the battlefield. But today, more than ever before, cities, villages, and towns are the battlefields, and it is children who get caught in the crossfire. Falling witness or victim to acts of war and terrorism stirs an array of powerful human emotions. (Joshi \& O'donnell, 2003, p. 275)

As was stated in the related literature, the primary reason for migration to another country is found to be related to civil war breaking out in Syria in 2011 (Biçer, 2017), a very threatening reality in the world having damaging negative effects on the children, and unfortunately it takes quite a while to overcome. The number of Syrian children residing in Turkey is quite high. The total number of Syrian children involved in education is 1.179.264. The negative effects of the war on immigrant children start to be experienced as a myriad of feelings as soon as they migrate to the host country and these feelings are not typical of childhood (Joshi \& O'donnell, 2003). The negative effects of this situation cause the children to experience adaptation difficulties in all areas of life and the field of education is not immune from this adaptation period.

* This research has Ethics Committee Approval from Suleyman Demirel University with 02/02/2020 date and 102/2 number.

To cite this article: Tunaboylu,O., Vezir, M. \&Uluyol, A. (2021). The other face of the iceberg: The immigrant students in English courses and their teachers. International Journal of Social Sciences and Education Research, 7 (2), 106-113. DOI: https://doi.org/10.24289/ijsser.832591

Copyright (C) 2021 by IJSSER

ISSN: 2149-5939 


\section{Literature review}

Considering its geographical location, history and cultural background, Turkey is seen as a good place to start a new life for many people suffering from traumatic events. According to TÜIK's report published in 2018, there has been a flow of immigrants to Turkey especially from Eastern countries, such as Iraq, Afghanistan, Syria, Turkmenistan, Azerbaijan and so on. As can be seen, the top three countries are the ones dealing with war. Among these people, children are the most vulnerable group that needs immediate care both mentally and physically. Once refugees have met their basic need for food, water and shelter, their primary concern is to ensure that their children can attend school (Tösten et al., 2017).

When we look at recent history, during the outbreak of Syrian civil war in 2011, refugees were provided with shelters along with temporary education centers. However, as time went by, most of them moved from tent camps and started to live in city centers. The current number of refugees who are between 0-18 is 1.694.520 (Özdemir, n.d.). As stated in a recent circular about the PIKTES (Project on Promoting Integration of Syrian Kids into The Turkish Education System) published by the National Ministry of Education, refugee children were given a right to choose between temporary education centers, public schools and private schools (Project on Promoting Integration of Syrian Kids into The Turkish Education System, 2017). As the aim of the project is to support social cohesion during temporary protection in Turkey, different kinds of training for both families and students are included. Turkish and/or English Language Education, Early Childhood Education, Catch-up and Back-up training are the examples for this. However, these types of activities and awareness do not only help refugee children but also their families. For example, Turkish Language Education for Syrian Families is provided.

As stated by Lustig (2004), these children distress over rapid cultural changes besides a new language. The language and culture are intricately interwoven so that one cannot separate the two without losing the significance of either language or culture (Saniei, 2012).

As a result of the process of adapting to a new culture and learning a new language, the process of acculturation is observed to take place and later to be followed by assimilation (Kosic, 2002). However, in today's world, immigrants prefer to preserve their language and culture while adapting. This results in pluriculturalism (Birman \& Addae, 2016). For example, the immigrant families tend to go to Syrian restaurants where they can eat their national dishes whereas they might also be a kind of mediator between two cultures by taking some of their friends out to a dinner at a Syrian restaurant. In this case, they mediate between two groups as interpreters and thus become intercultural people (Byram \& Golubeva, 2020). However, this happens only when immigrants know host country language. Therefore, not knowing the language of the host country leads immigrant children to be isolated from their classmates and feel lost in a different culture. No matter how similar their cultures are to the host country, being illiterate sets a big barrier before immigrants and does not help them with adapting to a new culture, which is concluded based on one of our participant's experiences. Adapting to the host country's cultural norms appears to be one big problem for both children and the teachers who try to provide education with immigrants.

The illiteracy or feeling of isolation brings us to the point where teachers observe misbehaviors in these children towards their peers. It is important to keep in mind that these kids are in need for psychological aid. Additionally, as Lustig (Lustig et al., 2004) states, when this need is not met, it causes bigger difficulties like violence in public or at schools. Thus, teachers have to cope with these issues and help them integrate into society. Schools play a very important role in integration of these students because it is their first step in the acculturation process. They try to live in harmony with others and adapt to a new culture while handling the biases held by the society. It is nothing new to see migrants to be excluded in the host country. It takes time for both parties to learn to live together and break down their prejudices. This kind of inclusive approach creates a sense of belonging in children and affects their academic success positively as well (Oikonomidoy, 2010).

\section{Methodology}

This study adopted qualitative research design and is based on the Grounded Theory by (Green et al., 2007). The Grounded Theory is based on grouping the views of participants according to the frequency of certain items under similar categories. It aims to establish a theory in regard to field evidence. This seeks to offer suggestions and a conceptual explanation to the lacking parts that the participants add to the investigated phenomenon. Therefore, in the study we tried to investigate difficulties encountered in the language classrooms which include immigrant children. 


\subsection{Participants and context}

Purposeful sampling procedure was utilized. English language teachers were selected from those who volunteer and have teaching experience in classrooms with immigrant students. A total of 6 female Turkish teachers of English volunteered to participate in this study. They have been working at state schools in the city center of Isparta. The participants represented each level of instruction, that is, 2 teachers from primary school, 2 teachers from middle schools and 2 teachers from high school. Teachers were named as T1, T2, T3, T4, T5, and T6. T1 and T2 were primary school teachers, T3 and T4 were middle school teachers and T5 and T6 were high school teachers. They had teaching experience at state school for a minimum of 8 years to 33 years. Teachers stated that they had been working with immigrants minimum for 5 years.

\subsection{Instruments}

Semi-structured interviews were used to collect data. Interviews have a continuum. Structured interviews follow a list of questions predetermined and standardized. The questions are always asked in the same order and in almost the same way. However, unstructured forms of interviewing such as oral histories are at the other end of the continuum. In these interviews, the conversation is generally guided by the informant rather than by the questions placed. Semi-structured interviews are in the middle of this continuum. This form of interviewing has a certain degree of predetermined order but still ensures flexibility in the way the informant addresses issues (Longhurst, 2003). The researchers tried to obtain a better understanding of the encountered difficulties by getting in touch with English language teachers who had been witnessing the situation from the first hand.

The study primarily aimed at finding out the difficulties faced by the English language teachers and the strategies developed and employed successfully by these teachers. More specifically, the study was conducted to obtain answers for the following research questions:

1) What are the major difficulties Turkish teachers of English encounter on an everyday basis?

2) What strategies have Turkish teachers of English developed over the years to overcome these difficulties?

3) What are Turkish English teachers' opinions about the new program introduced by the MoNE? Could you please assess immersion programs, which are newly introduced by the National Ministry of Education, with their strengths and weaknesses?

4) What are the recommendations of the teachers to improve the current situation?

\subsection{Data collection procedure}

Interviews were arranged by one of the researchers and took place in participants' schools. The answers were audiotaped with the consent of the contributors and transcribed later. The interviews were conducted in Turkish so as to maximize the strength of expression. According to Krashen's Theory of Affective Filter as cited in Schütz (Schütz, 2007), speakers have the tendency to filter their emotions and real thoughts while using a foreign language. Therefore, the researchers preferred to use participants' native language and made sure there was no loss of meaning in translations. After transcription, the interview documents were translated from Turkish into English by the researchers. Each interview approximately lasted 25-30 minutes.

\subsection{Data analysis}

Semi-structured interviews enable participants to answer the questions more flexibly and thus they can express themselves better. As the interviews were semi-structured type, the researchers used a cross-interview analysis technique to analyze the data gathered from the interviews. The methodology for the cross-interview analysis involves grouping the responses to the same or common subject from different people. The researcher read each interview several times and summarized the responses. As a result of cross-interview analysis, three broad categories were generated. Along with these broad categories two sub-categories emerged. The findings for each category were presented with accompanying quotations from the participants. Then, three main categories, which are communication difficulties (CP), cultural incompatibility $(\mathrm{CI})$ and curriculum \& parent pressure (CPP), were created. Two related subcategories also emerged since the researchers wanted to shed light upon some specific areas. They were named as "not knowing Turkish \& being illiterate, biases". In order to see different aspects related to the subcategories, interview transcripts were re-read, and each detail was taken into consideration. The analyzed data were presented under categories and with appropriate quotations from the participants. 


\section{Results}

The present study primarily aimed at investigating the major difficulties faced by Turkish teachers of English in classrooms with immigrant students. The study also looked at the strategies which teachers developed to overcome these difficulties. As mentioned earlier, immigration is a very significant reality in Turkey. As of 2020, the total number of Syrian children reached 1.694 .520 as of (Özdemir, n.d.). As revealed in Table 1, the number of Syrian children residing in Turkey is quite high. The total number of Syrian children involved in education is 1.179.264.

Table 1. Actual Number of Syrian Refugees Residing in Turkey- October 2020

\begin{tabular}{cccc}
\hline Age range & Male & Female & Total \\
\hline $0-4$ & 255.900 & 247.400 & 503.300 \\
$5-9$ & 282.602 & 259.721 & 542.322 \\
$10-14$ & 203.410 & 184.596 & 388.006 \\
$15-18$ & 142.058 & 118.556 & 260.614 \\
\hline
\end{tabular}

In order to address the purposes of the study, four open-ended questions were asked. Based on the data analysis, it can be stated that several difficulties were frequently voiced by the participant English language teachers. The researchers compiled these difficulties under 5 main headings:

(1) Communication-related difficulties

(a) Not Knowing Turkish and Being Illiterate

(b) Behavioural Problems

(2) Cultural incompatibility

(a) Biases

(3) Curriculum and Parental Involvement

Each broad category will be presented in the rest of the paper with proper quotations.

\subsection{Communication-related difficulties}

It is worth bearing in mind that communication difficulties in classrooms may get bigger in the future if ignored. It is very important to notice them on time and take the necessary measures. Since communication is a basic need in human life, it is very important for the child to understand the environment in which he lives and to be able to communicate with those around him. As can be seen in Table 1, the number of immigrant children who are at the stage of adolescence is high. According to Erikson's Psychosocial Development Theory, adolescence is the most important stage in one's development since it is the period when the identification process begins. The disruption in this stage badly affects people's future communication (Rosenthal et al., 1981). Failed communication causes the child to show behavioural problems. The child becomes aggressive, disrupts the order of the class and disturbs his friends. Parents who are refugees in Turkey have achieved an impressive task: they have escaped war, persecution, and maybe death in order to bring their children to a safe place (Dumbrill, 2009). Refugee parents, who have difficulties with adapting to the new country in which they started to live, neglect to take care of their children adequately. Maslow (McLeod, 2007) states that people are motivated when their certain needs are met, such as food and shelter. When one need is met, a person aims to fulfil another one. It is said that the deficiency, or basic needs, demotivates people. Also, the longer they are denied, the need to meet those needs will become stronger. Before moving forward with satisfying higher-level growth needs, one must satisfy lower-level needs. If these needs have been fairly fulfilled, one will be able to reach the highest level, called self-actualization. As the family has difficulty in meeting these basic needs, they cannot move to the upper levels. This is one of the factors that cause children to try to cope with their communication difficulties and behavioural problems alone and they generally fail to do it. The trauma caused by civil war or migration and financial inadequacies can also lead to communicative and behavioural problems.

Quotations from interviewee teachers about communication difficulties and behavioural problems:

37-year-old Turkish teacher of English with 15 years of teaching experience, mentioned the communicationrelated difficulties. Almost all 6 of the participants mentioned 'communication' as a major difficulty.

T1: 'There is really a big behavioural disorder, so as I said, refugee students have a war-based background. They run away; they fear from each other. Some of them talk in the groups that they were afraid of while fleeing, and they constantly hear this kind of conversation from their family. Of course, the child reflects this. He thinks 
he can protect himself by fighting. Therefore, instead of talking or complaining to the teacher when the problem arises, he directly pinches, pushes and spits at his friend. These were the biggest problems that other classroom teachers and I observed during our classes.

T2: We have problems in terms of communication. Students have difficulty in understanding the instructions. The biggest problem is that students have adaptation problems during the lesson. Even if you work in English you generally have to give the instructions in Turkish. They cannot understand Turkish either. If there is not a student in the classroom who understands the instruction and translates it to his friends, the problem increases substantially. Our biggest problem is that we cannot get along, we cannot find the common point. We have behavioural problems. Student disturbs his friend. He pulls her hair. He begins to shout or tries to interfere with the class. He says, "I want to go out." As they are coming from a war environment, they try to protect themselves by beating their friends. They perpetrate violence to their friends. This is the biggest problem encountered in our schools. Psychological problem.

\subsection{Cultural incompatibility}

Cultural incompatibility is another issue that needs to be considered. The child's inability to recognize the culture of the host society in which he started living and to adapt to it makes him feel like he does not belong there. Not understanding the jokes and not making sense of cultural discourses make the child feel bad. We can say that this situation prepares a base for the child to show behavioural problems.

Individuals from various communities or countries have specific goals, beliefs and desires influenced by their cultural factors. Indeed, in intercultural friendships, individuals feel less threatened to share a common culture, language, religion, values and institutions. Therefore, cultural incompatibility will grow from fear and indifference to the actions of others and from the prejudice and discrimination (Craig, 2016). Even though immigrants' efforts to survive in a country that has a different culture from their own culture is the first step to alleviate cultural incompatibility, it is not entirely sufficient. It is quite normal to experience a painful process during the habituation phase.

Quotations from interviewee teachers about cultural incompatibility:

T1: Incompatibility to class's culture, school's culture and the environment's culture, which is surrounding the child, is a huge problem for us. The students go through a trauma of course. Even if some of them have not seen the war, the traumas that their family experience pass on to the child. They also come to a new country. They meet new people. They internalize some of them. Being adopted by the teacher or not being adopted by the teacher, all of these create a trauma on children. And at the beginning they develop a negative attitude towards the class and towards the school. Keeping their motivation alive is more difficult compared to normal students.

T3: Problems that I encounter on the basis of foreign students I can list them as follows:

- Low level of education of parents,

- Family's neglection

- Lack of material goods due to lack of financial means and budgetary concerns

- $\quad$ The student does not know Turkish or is illiterate.

- Cultural differences

Foreign students come to Turkey without knowing Turkish. Their native language Arabic operates on an alphabet that is totally different from the Latin alphabet that the Turkish language is utilizing. These refuge children who receive formal schooling are literate in their native languages. When they migrate to Turkey and start school with their peers, they are like illiterate people. According to the program initiated by the MoNE mentioned earlier, regardless of their ages all refuge children are enrolled in Turkish reading/writing classes with their 7-year-old Turkish peers before they start education. Numerical system in their own alphabet is also different. Foreign students need to learn these concepts first.

Quotations from interviewee teachers about Not Knowing Turkish and Being Illiterate:

T4: They are trying to adapt but I guess their need is a more basic Turkish education. If we take them directly to a normal class, they can be confused.

As Einstein said, "Breaking biases is more difficult than breaking down an atom." The prejudices we have developed as a normal human behaviour can generally make us think in a negative way. It is totally normal to have 
prejudices but letting them control our behaviours may cause adverse effects. Students' biases towards one another make them think and behave negatively. They carelessly use offending words towards each other as they cannot truly control their biases, but their biases control them.

Quotations from interviewee teachers about Biases:

T2: Unfortunately, we have a prejudice. We do not have it in our school, but we hear from our colleagues. Some parents say 'I do not want my child to sit with a Syrian child. 'or' I do not want my child to be friends with a Syrian child.' Breaking this bias is very hard. Sometimes even the teachers have some biases. They ask, 'Why are there so many foreign students?' The teacher says that 'I taught to my students how to read and write (Neither strangers nor Turkish are distinguished anyway.) Today a new student came to my class and he is illiterate. What am I going to do now?' Now in each class there are newcomers, who started education at the middle of the semester. These are big problems. You cannot ignore them or put them behind the class and not care about them. What will the child do there? He will get bored and start to disrupt the class order. In some families, especially at the houses of Somalian immigrants, we see that anything spoken in the house reflects to the child directly. Some of the immigrants may have biases as well. They have a thought like Turkey is helping us, but it has its own benefits from this situation. We try to explain the true point of view to the child as far as possible. We say this is a wrong statement and a wrong thought. As far as I understood channels that they watch at home or journals and printed media that they follow trigger their biases.

T5: As you know breaking the bias is harder than breaking the atom. It does not happen immediately, but I think we will achieve it gradually. Our students are very nationalistic. As there are a lot offoreign students coming from Iraq, Iran, Somalia, Syria, Afghanistan, Libya, Egypt and so on. Turkish students become surprised. They ask "Is Turkey the only place that they can live? Why are these people here?" They definitely have biases, but I try to explain to them that women and children do not have another choice, I tell them how bad the war environment is and sometimes to convince them I ask foreign students to talk about their country's situation.

Even while working with students who share the same language and same culture as you, curriculum and parent pressure cause malfunctions in the process. With the inclusion of foreign students in our education system, the curriculum, exam and family pressure affect the process even more negatively. As foreign students do not know the language and the culture of this new country the teacher feels like dealing with the foreign students individually. However, the teacher has a curriculum to follow and the exam pressure causes parents to apply a pressure on the teacher. As a result, the teacher is not able to manage the process as he/she wishes.

Quotations from interviewee teachers about Curriculum and Parent Pressure:

T4: If we teach in a way that even disabled and foreign students can understand, everyone will benefit from it. If we do not have concerns about LGS (Transition to High School Exam), trial exams, curriculum and parent pressure, we would feel much more comfortable and we would have done a more correct education.

\section{Discussion}

Immigrants' children are psychologically traumatized, and they have not been able to overcome it yet (Joshi \& O'donnell, 2003). However, they try to survive in a completely new country and try to adapt to its people. While all they need is to restore their well-being, they face conflict with local people. This worsens the crisis in them. They are expected to attend school, adapt to the new educational system, which is totally different for them, and keep schools' and teachers' expectations above their basic needs, whereas their living conditions have not reached to its normal standards yet. About this issue, Turkish Ministry of Education (MEB) initiated PIKTES Project, whose main aim is to promote access to education in Turkey for children under temporary protection and to support their social cohesion. It also aims to support MEB's efforts on education and social cohesion of children under temporary protection. It can be accepted as the first step towards solving this problem. As part of PIKTES, students are expected to stay in integration classes for a certain period of time and reach a level of proficiency in Turkish. In these classes students only have Turkish, sport and art classes. At the end of each semester, Turkish proficiency exams are held and students who are observed to be above a certain level get the right to pass to normal classes. In this respect, these classes, which can be considered as an example of immersion education, may be counted very useful.

Even though their culture shows similarities with the host country, it is not easy to be part of the acculturation process. The biases that they encounter and they have do nothing but worsen the situation. According to the participating teachers, parents are the major sources of biases. Parents are the main reasons why immigrant students 
and peers of immigrant children have biases. They face these biases not only at school but also at mass media. Channels watched at their home and the newspapers read by their parents trigger the formation of hatred at immigrant children. These biases are double-sided as immigrant students are exposed to bullying by their Turkish peers. This does not help them to fix the bad image of the host country since they have a perception that "We are in a bad condition, but Turkey is helping us for its own sake".

When students are asked about the source of this idea, they have some expressions like "Turkey is receiving payment from the European Union for keeping us in their country". Since parents are the main reason for the biases that students have, holding family elucidating seminars can be a suitable and feasible solution. In these seminars, the difficult situations experienced by immigrants can be addressed by going through certain topics. Immigrants, who have witnessed the incident, may share their experiences. Indulgence and tolerance may be suggested. Teachers cannot do anything but suggest Turkish students to be tolerant and try to change the negative image that Turkey has in the minds of immigrant children because teachers are not supported enough, either. Parents also make their jobs harder and do not assist teachers to integrate students into the educational system. This problem can be solved by assigning each student a buddy who will help them with anything they need. Before this process, it would be better to educate students about intercultural communicative competence. In this way, students will be informed about what their peers will need and why this is necessary. How they will be paired is up to the teacher's preference. It can be a natural process where students find each other a partner. However, teachers' selecting the pairs can be used in situations in which students are reluctant to get to know each other. In this way, it will ease teachers' burden and students will become friendly at once.

Sociocultural integration often refers to learning about a culture, behavioural adequacy and exchanges, psychological integration refers to coping with the new environment, social support, solidarity and overall all psychological well-being (SSeker \& Sirkeci, 2015). Community's support is crucial in the soundness of the orientation process. Researcher's solution for this problem is to have orientation programs for immigrant families. These programs can be conducted by municipalities or Non-Profit Organizations (NGO). In these programs, families will be provided with any kind of information they will need to survive. Germany has successful applications in this field. It has programs that aim to help immigrants with many issues, such as shopping, dealing with language difficulties and societal relations. They fasten the adaptation process of immigrants. A similar kind of orientation process may also be held at schools. A concept called "Turkish Hours" may be useful. It may be designed as "European Hours", which is popular in Europe. In the "European Hours" lessons using the vehicular language, the integration and harmonization of students from different nationalities is formally achieved. "European Hours" is an essential elementary school curriculum feature from grade 3. Kids from different language backgrounds work together in groups of 20 to 25 students for three lessons a week. Students generally have a cognitively undemanding and attainable goal, like making puppets. This can be adjusted to Turkish context by making use of our own cultural elements. For example, students might spend their time learning folklore dances such as Atabarı or Zeybek, watching cartoons like Pepe etc. City trips may be organized during school hours to museums or historical places.

Psychological growth mediates the effect of war and persecution, relocation among immigrant and refugee youth, reliant on the decisions of adults and at the mercy of political chaos and unpredictable violence (Lustig et al., 2004). If the precautions are not taken on time, these children will waste their time, and this will affect their future and surroundings negatively.

\section{Conclusion}

As mentioned earlier, while conducting this research, there have been some changes in the area, such as including new types of activities in PIKTES program. Therefore, keeping up with the recent changes was the hardest part. Additionally, as we worked with very few participants in a small town in Turkey, the findings of the study cannot be generalized beyond this sample and context. Thus, a further study could be administered by using a larger sampling. Even though we tried to create a variety of participants, the ones at high school level were only from Imam Hatip High School because of convenience issues and reluctance of the teachers. As the last thing, we wanted to run a study based on Intercultural Communicative Competence (ICC), but the results of the interviews took us to a very different point.

\section{Acknowledgements}

We would like to thank all the teachers who spared time to help us with our research. 


\section{Author contribution statements}

O. Tunaboylu, M. Vezir \&A. Uluyol contributed equally to the design and implementation of the research, to the analysis of the results and to the writing of the manuscript.

\section{Disclosure statement}

No potential conflict of interest was reported by the authors.

\section{Ethics committee approval}

This research has Ethics Committee Approval from Suleyman Demirel University with 02/02/2020 date and 102/2 number. All responsibility belongs to the researchers. All parties were involved in the research of their own free will.

\section{References}

Biçer, N. (2017). The Views of Syrian Refugees Migrating to Turkey on the Turkish Language and Culture: Kilis Case. Journal of Education and Training Studies, 5(3), 97. https://doi.org/10.11114/jets.v5i3.2100

Birman, D., \& Addae, D. (2016). Acculturation. In Transitions: The Development of Children of Immigrants (pp. 122-141).

Byram, M., \& Golubeva, I. (2020). Conceptualizing intercultural (communicative) competence and intercultural citizenship. In The Routledge Handbook of Language and Intercultural Communication (pp. 85-99).

Craig, J. (2016). How can cultures be incompatible? https://doi.org/10.13140/RG.2.2.35071.87203

Dumbrill, G. C. (2009). Your policies, our children: Messages from refugee parents to child welfare workers and policymakers. Child Welfare, 88(3), 145-168.

Green, D. O., Creswell, J. W., Shope, R. J., \& Clark, V. L. P. (2007). Grounded theory and racial/ethnic diversity. The Sage Handbook of Grounded Theory, Part V, 472-92.

Joshi, P. T., \& O'donnell, D. A. (2003). Consequences of child exposure to war and terrorism. Clinical Child and Family Psychology Review, 6(4), 275-292.

Kosic, A. (2002). Acculturation Attitudes, Need for Cognitive Closure, and Adaptation of Immigrants. The Journal of Social Psychology, 142(2), 179-201. https://doi.org/10.1080/00224540209603894

Longhurst, R. (2003). Semi-structured interviews and focus groups. Key Methods in Geography, 3(2), 143-156.

Lustig, S. L., Kia-Keating, M., Knight, W. G., Geltman, P., Ellis, H., Kinzie, J. D., Keane, T., \& Saxe, G. N. (2004). Review of Child and Adolescent Refugee Mental Health. Journal of the American Academy of Child \& Adolescent Psychiatry, 43(1), 24-36. https://doi.org/10.1097/00004583-200401000-00012

McLeod, S. (2007). Maslow's hierarchy of needs. Simply Psychology, 1, 1-8.

Oikonomidoy, E. (2010). Zooming into the school narratives of refugee students. Multicultural Perspectives, 12(2), 74-80. https://doi.org/10.1080/15210960.2010.481186

Özdemir, A. S. (n.d.). Türkiyedeki Suriyeli Sayısı Ekim 2020 - Mülteciler Derneği. Retrieved November 18, 2020, from https://multeciler.org.tr/turkiyedeki-suriyeli-sayisi/

Qouta, S., Punamäki, R.-L., Miller, T., \& El-Sarraj, E. (2008). Does war beget child aggression? Military violence, gender, age and aggressive behavior in two Palestinian samples. Aggressive Behavior: Official Journal of the International Society for Research on Aggression, 34(3), 231-244.

Rosenthal, D. A., Gurney, R. M., \& Moore, S. M. (1981). From trust on intimacy: A new inventory for examining Erikson's stages of psychosocial development. Journal of Youth and Adolescence, 10(6), 525-537.

Schütz, R. (2007). Stephen Krashen's theory of second language acquisition. English Made in Brazil, 2(2), 2007.

Şeker, B. D., \& Sirkeci, I. (2015). Challenges for Refugee Children at School in Eastern Turkey. ECONOMICS \& SOCIOL$O G Y, 8(4), 122-133$. https://doi.org/10.14254/2071-789X.2015/8-4/9

Suriyeli Çocukların Türk eğitim Sistemine Entegrasyonun Desteklenmesi Projesi. (2017). https://piktes.gov.tr/

Tösten, R., Toprak, M., \& Kayan, M. S. (2017). An Investigation of Forcibly Migrated Syrian Refugee Students at Turkish Public Schools. Universal Journal of Educational Research, 5(7), 1149-1160. https://doi.org/10.13189/ujer.2017.050709

UNHCR Türkiye İstatistikleri-UNHCR Country. (n.d.). UNHCR. Retrieved June 13, 2020, from https://www.unhcr.org/tr/unhcr-turkiye-istatistikleri 